\title{
Experimental Investigation on Creep Forming of A New Al-Li-Cu-Mg
}

\section{Alloy Plate}

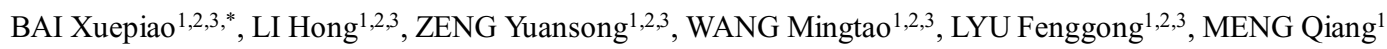 \\ ${ }^{1}$ AVIC Manufacturing Technology Institute \\ ${ }^{2}$ Aeronautical Key Laboratory for Plastic Forming Technology \\ ${ }^{3}$ Beijing Key Laboratory of Digital Plasticity Forming Technology and Equipment \\ ${ }^{*}$ Corresponding author: baixp@163.com
}

\begin{abstract}
Fundamental creep forming experiments on a new Al-Li-Cu-Mg alloy plate were carried out to investigate the forming parameters of integral reinforced panel with thin skin. The effects of process parameters on springback ratio and material properties are investigated by orthogonal design method. The result data show that the springback ratio decreases with the temperature and time period of creep age forming, increases with radius of pre-bend. The tension strength and yield strength increase and then decrease with temperature of creep forming. The elongation decreases with the temperature of creep forming. A mathematical equation model for springback ratio is proposed and resolved thorough regression analysis method. A typical structure of fuselage panel is creep formed, which verified the effectiveness and accuracy of the mathematical equation model.
\end{abstract}

Key Words: Metal forming; Alloy; Thermal effects;

\section{Introduction}

Aluminium-lithium(AL-Li) alloys has comprehensive advantages including relatively low density, high elastic modulus, high specific strength and stiffness, excellent fatigue strength, superior corrosion resistance and good weld ability, and lower cost than composite materials. After three generations of development, the new Al-Li alloys are applied in modern aerial and space vehicles to meet their requirement of weight reduction [1-4]. For example, Aluminium alloy AA2124 is replaced by Al-Li alloy 2197 in the rear fuselage and other parts of F-16 Fighting Falcon to reduce weight for $5 \%$, improve fracture toughness for 7\% [5-6]. Almost all parts for fuselage of Bombardier's C Series airplanes are manufactured by Al-Li alloys, and its Al-Li alloy usage rate accounts for 23\% of aircraft materials. Al-Li alloy 2060 is applied to fuselage of C919 airplane of China for reducing weight.

Creep forming is a kind of new manufacturing technology, which restrain a component to a specific shape during heat treatment allowing the component to relieve stresses and creep to contour. There are many advantages for creep forming, including lower residual stress, good shape stability, high stress corrosion resistance, good surface quality and so on. Thereby, it can be applied to manufacture skin components and integral stiffened panels of airplane [7-10].

In this study, fundamental creep forming experiments are carried out on a new $\mathrm{Al}-\mathrm{Li}-\mathrm{Cu}-\mathrm{Mg}$ alloy. After just one heat treatment process, the material is age-hardened, and the part is also shaped. The effect of creep aging parameters on springback rate is studied, and a function relationship between springback rate and the process parameters is obtained. Experiment on typical part of welding fuselage panel is used to validate the model, which establish the technical basis for the manufacturing of large Al-Li alloy structures especially of welded fuselage panels.

\section{Fundamental creep forming experiment}


The experiment material is a new kind of $\mathrm{Al}-\mathrm{Li}-\mathrm{Cu}-\mathrm{Mg}$ alloy which is aged to T8 status, with $\mathrm{t}=1.8 \mathrm{~mm}$ in thickness. Its chemical components are listed in table 1, and its mechanical properties in longitudinal direction (LD) and transversal direction (TD) of rolling fibre at room temperature are listed in table 2 which shows a little anisotropy properties.

Table 1. Chemical components of the new Al-Li alloy

\begin{tabular}{|c|c|c|c|c|c|c|c|c|c|}
\hline $\mathrm{Al}$ & $\begin{array}{c}\mathrm{Si} \\
\%\end{array}$ & $\begin{array}{c}\mathrm{Fe} \\
\%\end{array}$ & $\begin{array}{c}\mathrm{Cu} \\
\%\end{array}$ & $\begin{array}{c}\mathrm{Mn} \\
\%\end{array}$ & $\begin{array}{c}\mathrm{Mg} \\
\%\end{array}$ & $\begin{array}{c}\mathrm{Zn} \\
\%\end{array}$ & $\begin{array}{c}\mathrm{Zr} \\
\%\end{array}$ & $\begin{array}{c}\mathrm{Ti} \\
\%\end{array}$ & $\begin{array}{c}\mathrm{Li} \\
\%\end{array}$ \\
\hline Bal. & $\leq 0.05$ & $\leq 0.07$ & $3.4 \sim 4.2$ & $0.10 \sim 0.50$ & $0.6 \sim 1.1$ & $0.30 \sim 0.45$ & $0.10 \sim 0.50$ & $0.6 \sim 0.9$ & $0.04 \sim 0.18$ \\
\hline
\end{tabular}

Table 2. Mechanical Properties of the new Al-Li alloy

\begin{tabular}{cccccc}
\hline Materials & $\begin{array}{c}\text { Tension } \\
\text { Direction }\end{array}$ & $\begin{array}{c}\text { Tensile strength } \\
\mathbf{M P a}\end{array}$ & $\begin{array}{c}\text { Yield strength } \\
\mathbf{M P a}\end{array}$ & $\begin{array}{c}\text { Elongation } \\
\mathbf{\%}\end{array}$ & $\begin{array}{c}\text { Modulus of elasticity } \\
\mathbf{G P a}\end{array}$ \\
\hline \multirow{2}{*}{$\mathrm{Al}-\mathrm{Li}-\mathrm{Cu}-\mathrm{Mg}$} & $\mathrm{LD}$ & 520.2 & 491.2 & 16.1 & 74.1 \\
\cline { 2 - 5 } & $\mathrm{TD}$ & 514.2 & 424.8 & 19.8 & 74.72 \\
\hline
\end{tabular}

Key parameters influencing the creep forming result are target material thickness, temperature of creep forming, time period of creep forming, radius of pre-bend. Orthogonal design method is used to setup experiments due to the quantity of influence factors. In this paper, as the target material thickness is fixed, time period of creep forming (Factor A), temperature of creep forming (Factor B) and radius of pre-bend (Factor C) are selected as the designing variables with 4 response levels which are shown in Table 3. Experiments of variable creep forming parameters are carried out by the orthogonal array of $\mathrm{L}_{16}\left(4^{5}\right)$ [11] which are shown in Table 4. Pre-bend is imposed with special tool as shown in figure 1, then creep formed in electric thermostat-box. The dimensions of the test Al-Li alloy plates are $260 \times 70 \mathrm{~mm}$.

Table 3. Orthogonal array of experimental parameters

\begin{tabular}{cccc}
\hline \multirow{2}{*}{ Trials } & $\begin{array}{c}\text { Time Period } \\
\text { (hour) }\end{array}$ & $\begin{array}{c}\text { Temperature } \\
\left({ }^{\circ} \mathrm{C}\right)\end{array}$ & $\begin{array}{c}\text { Radius of Pre-bend } \\
(\mathrm{mm})\end{array}$ \\
\cline { 2 - 4 } & $\mathrm{A}$ & $\mathrm{B}$ & $\mathrm{C}$ \\
\hline 1 & 12 & 140 & 170 \\
2 & 16 & 160 & 190 \\
3 & 20 & 180 & 210 \\
4 & 24 & 200 & 230 \\
\hline
\end{tabular}

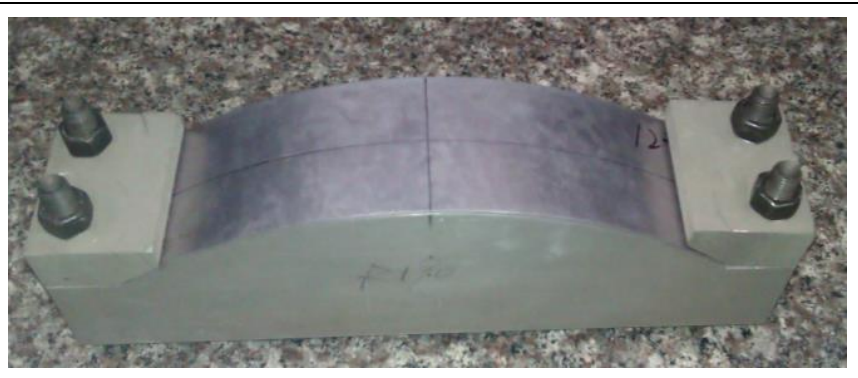

Fig. 1 Specimen in pre-bent

\section{Result and discussion}




\subsection{Springback ratio}

The contour precision of part component is one of the most important objective for sheet metal forming and creep forming is no exception. The general contour error is $0.5 \mathrm{~mm}$ or less for sheet panel component. Experiments are carried out to obtain the relationship between the process parameters and springback ratio (SR), which can established the fundamental technical base for precise creep forming. The effects of key parameters on creep forming in the dominant deforming direction are investigated using range method. The springback is defined as shown in figure 2 .

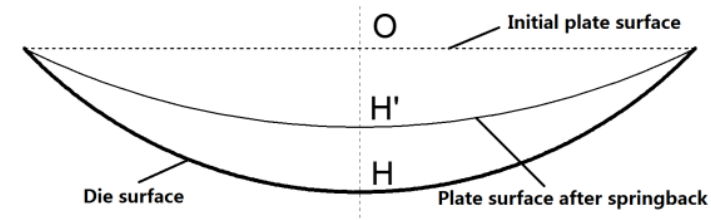

Fig. 2 Definition of springback

So the calculation of springback rate is shown as follows,

$$
S R=\frac{\overline{H H^{\prime}}}{\overline{O H}} \times 100 \%
$$

The experimental range analysis results are shown in table 4. In this table, $\mathrm{K}_{\mathrm{ij}}$ under column $\mathrm{A}$ is the sum of SR with $A_{i}(i=1,2,3,4), K_{i j}$ under column $B$ is the sum of $S R$ with $B_{i}(i=1,2,3,4), K_{i j}$ under column $C$ is the sum of $S R$ with $\mathrm{C}_{\mathrm{i}}(\mathrm{i}=1,2,3,4) . \mathrm{K}_{\mathrm{ij}} / 4$ is the average of $\mathrm{K}_{\mathrm{ij}}$. T means the sum of SR with the whole column. $\mathrm{R}_{\mathrm{j}}$ under column $\mathrm{A}$ is the difference between the maximum and the minimum of $\mathrm{K}_{\mathrm{ij}} / 4$ under column $\mathrm{A}$. Comparing the effect of each parameter on forming result, the most influential factor is the temperature of creep forming, the next is time period of creep forming, and the last is radius of pre-bent.

Table 4. Experimental data and range analysis results of creep forming

\begin{tabular}{|c|c|c|c|c|}
\hline \multirow[t]{2}{*}{ Range analysis results } & $\begin{array}{c}\text { Time Period } \\
\text { (h) }\end{array}$ & $\begin{array}{c}\text { Temperature } \\
\left({ }^{\circ} \mathrm{C}\right)\end{array}$ & $\begin{array}{l}\text { Radius of Pre-bend } \\
(\mathrm{mm})\end{array}$ & Springback ratio(\%) \\
\hline & A & B & $\mathrm{C}$ & SR \\
\hline 1 & $12(\mathrm{~A} 1)$ & $140(\mathrm{~B} 1)$ & $170(\mathrm{C} 1)$ & 97.12 \\
\hline 2 & $12(\mathrm{~A} 1)$ & 160 (B2) & $190(\mathrm{C} 2)$ & 93.46 \\
\hline 3 & $12(\mathrm{~A} 1)$ & 180(B3) & $210(\mathrm{C} 3)$ & 84.89 \\
\hline 4 & $12(\mathrm{~A} 1)$ & 200(B4) & $230(\mathrm{C} 4)$ & 73.36 \\
\hline 5 & $16(\mathrm{~A} 2)$ & $140(\mathrm{~B} 1)$ & $210(\mathrm{C} 3)$ & 97.26 \\
\hline 6 & $16(\mathrm{~A} 2)$ & $160(\mathrm{~B} 2)$ & $230(\mathrm{C} 4)$ & 94.63 \\
\hline 7 & $16(\mathrm{~A} 2)$ & 180(B3) & $170(\mathrm{C} 1)$ & 77.95 \\
\hline 8 & $16(\mathrm{~A} 2)$ & $200(\mathrm{~B} 4)$ & $190(\mathrm{C} 2)$ & 66.49 \\
\hline 9 & 20(A3) & $140(\mathrm{~B} 1)$ & $230(\mathrm{C} 4)$ & 94.63 \\
\hline 10 & $20(\mathrm{~A} 3)$ & 160(B2) & $210(\mathrm{C} 3)$ & 89.33 \\
\hline 11 & 20(A3) & 180(B3) & $190(\mathrm{C} 2)$ & 78.84 \\
\hline 12 & 20(A3) & 200(B4) & $170(\mathrm{C} 1)$ & 61.61 \\
\hline 13 & 24(A4) & $140(\mathrm{~B} 1)$ & $190(\mathrm{C} 2)$ & 93.98 \\
\hline 14 & 24(A4) & $160(\mathrm{~B} 2)$ & $170(\mathrm{C} 1)$ & 88.90 \\
\hline 15 & $24(\mathrm{~A} 4)$ & $180(\mathrm{~B} 3)$ & $230(\mathrm{C} 4)$ & 80.51 \\
\hline
\end{tabular}




\begin{tabular}{|c|c|c|c|c|c|}
\hline \multicolumn{2}{|c|}{16} & 24(A4) & $200(\mathrm{~B} 4)$ & $210(\mathrm{C} 3)$ & 60.28 \\
\hline \multirow{4}{*}{ Sum } & $K_{1 j}$ & 348.83 & 382.99 & 325.58 & \multirow{9}{*}{$\mathrm{T}=1333.24$} \\
\hline & $K_{2 j}$ & 336.33 & 366.32 & 332.77 & \\
\hline & $\mathbf{K}_{\mathbf{3 j}}$ & 324.41 & 322.19 & 331.76 & \\
\hline & $\mathbf{K}_{4 \mathbf{j}}$ & 323.67 & 261.740 & 343.13 & \\
\hline \multirow{4}{*}{ Average } & $K_{1 j} / 4$ & 87.2075 & 95.7475 & 81.395 & \\
\hline & $K_{2 j} / 4$ & 84.0825 & 91.58 & 83.1925 & \\
\hline & $K_{3 j} / 4$ & 81.1025 & 80.5475 & 82.94 & \\
\hline & $K_{4 j} / 4$ & 80.9175 & 65.435 & 85.7825 & \\
\hline Range & $R_{j}$ & 6.29 & 30.3125 & 4.3875 & \\
\hline
\end{tabular}

The influential ability of each parameter on creep forming can be obtained by the experimental data analysis. As shown is figure 3, the horizontal component is parameter level of each factor and the vertical component is the springback ratio which shows as $\mathrm{K}_{\mathrm{ij}} / 4$ in figure 3 . The springback ratio decreases with the time period of creep forming and the temperature, increased with the radius of pre-bend, which shows the viscoplastic deformation characteristic from T8 status.

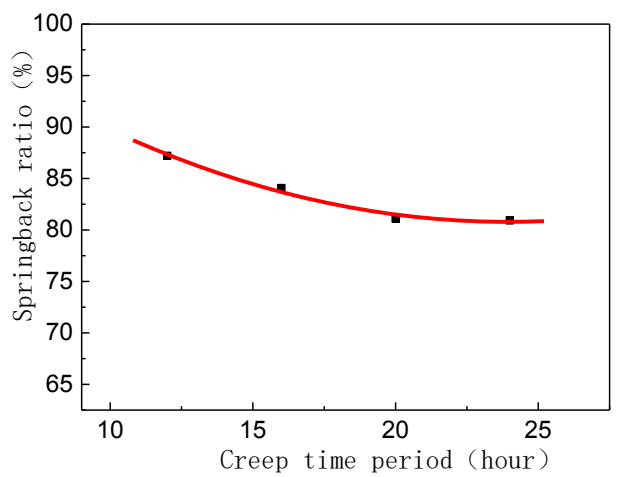

(A) Time period vs. springback ratio

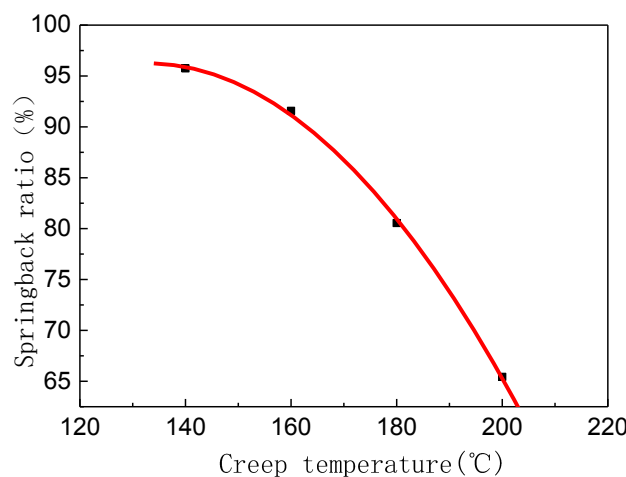

(B) Temperature vs. springback ratio

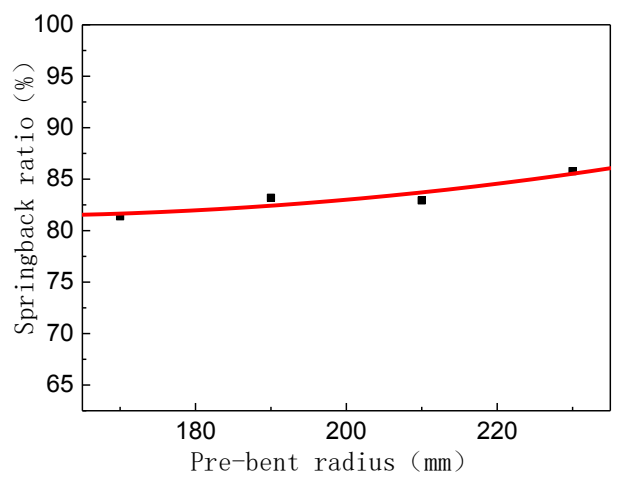

(C) Radius of pre-bend vs. springback ratio

Fig. 3 Relationships between parameters and springback ratio

The regressive analysis method is used to analyse the exact relationship between each parameters and springback ratio for optimization. The experiments are designed with 4 variables and 4 response levels, and each variable has an effect 
function as,

$$
\eta=\bar{\eta}+\varphi(A)+\varphi(B)+\varphi(C)
$$

where

$$
\bar{\eta}=\frac{1}{p} \cdot \frac{1}{n}\left(\sum_{i} y_{i}\right)
$$

and $\mathrm{p}$ is times of repetition, $\mathrm{n}$ is number of level.

Thorough the formula deduction, the equation with values for the relationship between springback ratio and process parameters is,

$$
\begin{aligned}
& \eta=\bar{\eta}+\varphi(A)+\varphi(B)+\varphi(C) \\
& =83.3275-0.54625(A-18)-0.50985(B-170)-0.0023\left(3 B^{2}-1020 B+85200\right)+0.06455(C-200)
\end{aligned}
$$

where $\mathrm{A}$ is time period of creep forming (hour), B is temperature of creep forming $\left({ }^{\circ} \mathrm{C}\right), \mathrm{C}$ is radius of pre-bend $(\mathrm{mm})$.

The equation model shows that the springback ratio decreases with the time period of creep forming and the temperature, increases with the radius of pre-bend, which are in agreement with previous analysis. Substituting the process values of experiments into the equation model, the regressive springback ratio are calculated and compared with the experimental data. As shown in Fig. 4, the regressive springback ratio from the equation model and the measured experimental data are very close. So this equation model derived from experimental data is accurate and can be referenced in engineering manufacturing.

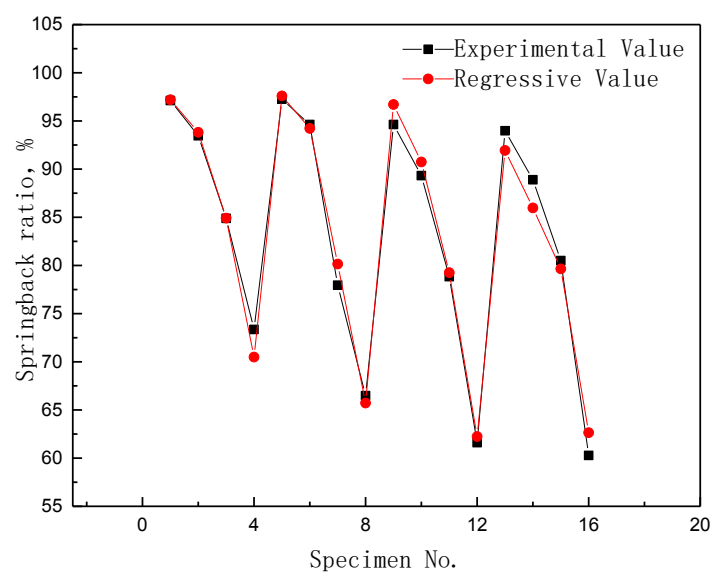

Fig. 4 Comparison of the regressive and experimental springback ratio

\subsection{Material property test}

Specimens of uniaxial tension test are heat treated with the fundamental experiment as well. The influence rule of the process parameters on material properties are shown in Fig. 5 and Fig. 6. The tension strength, yield strength and elongations rate of TD direction decrease with time period of creep forming. The tension strength and yield strength of LD direction decrease and then increase with time period of creep forming. Elongation of LD direction increases and then decreases with the time period of creep forming. The tension strength and yield strength of both directions increase and then decrease with temperature of creep forming. Elongation decreases with the temperature of creep forming. 

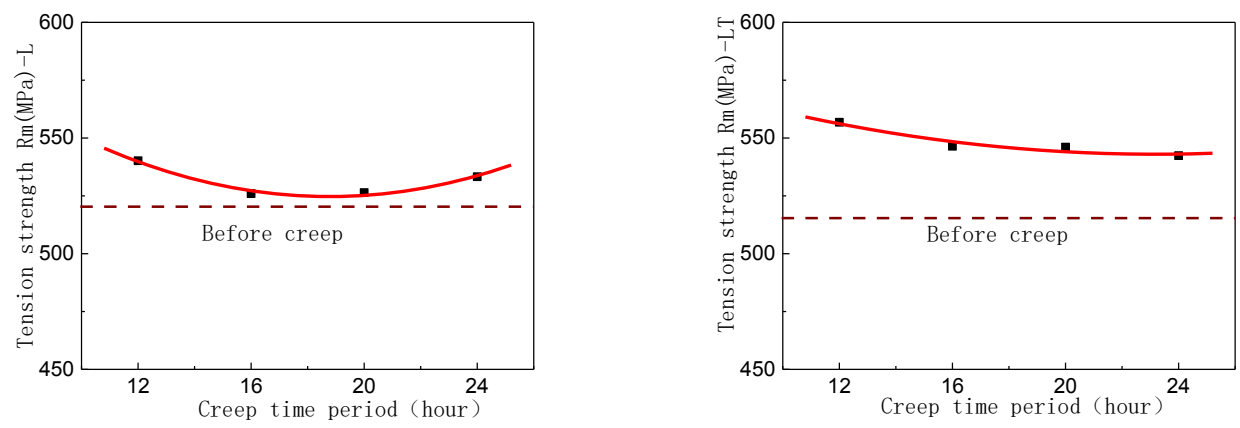

(a) Creep time period vs. Tension strength
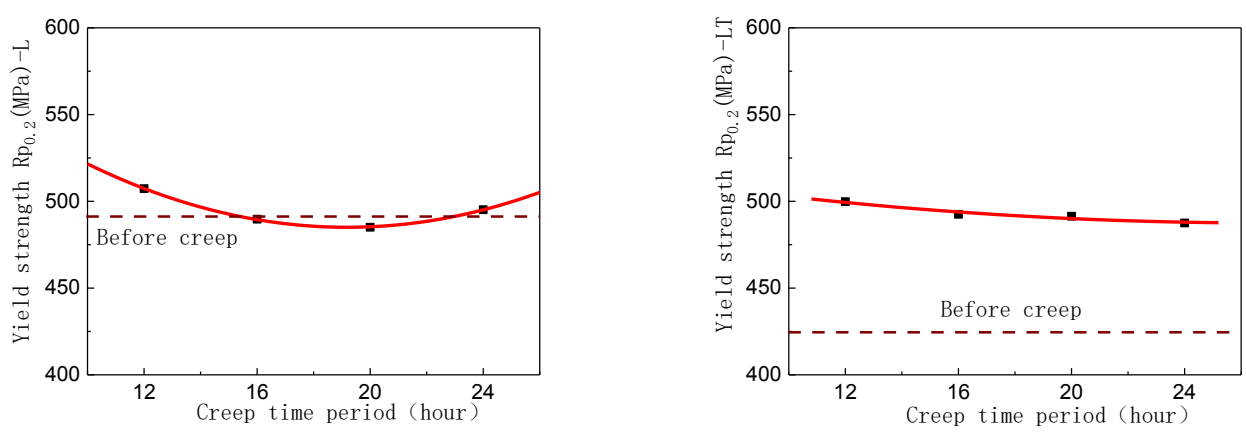

(b) Time period vs. Yield strength
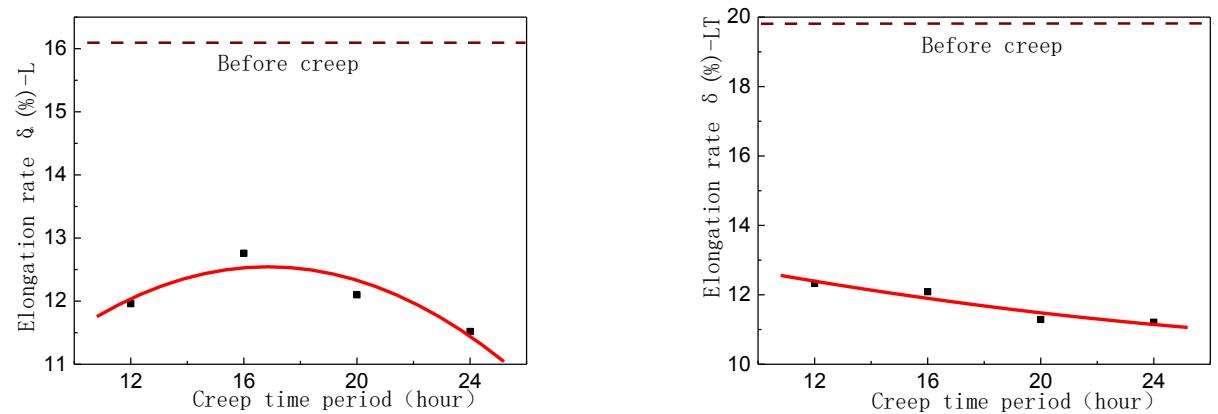

(c) Time period vs. Elongation rate

Fig. 5 Relationships between creep time period and material properties
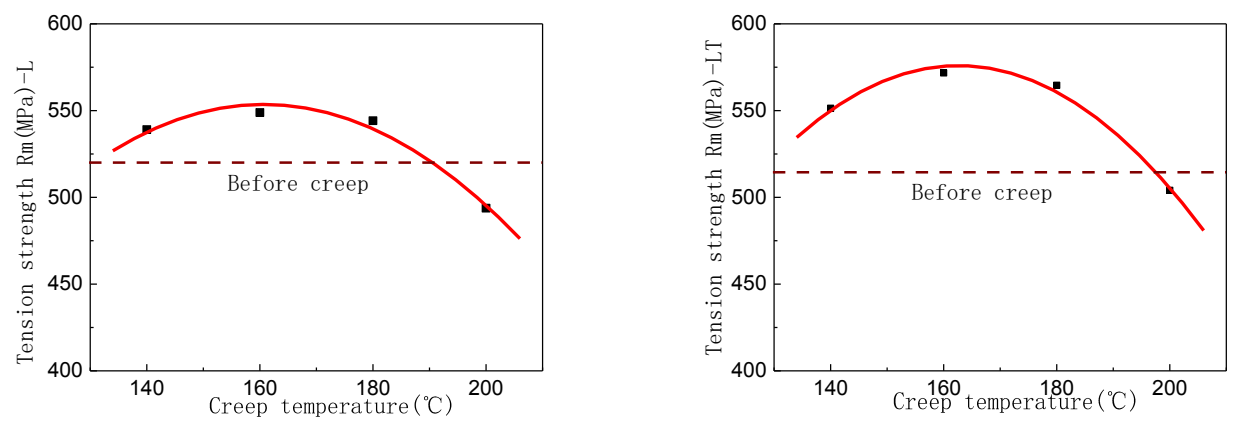

(a) Creep temperature vs. Tension strength 

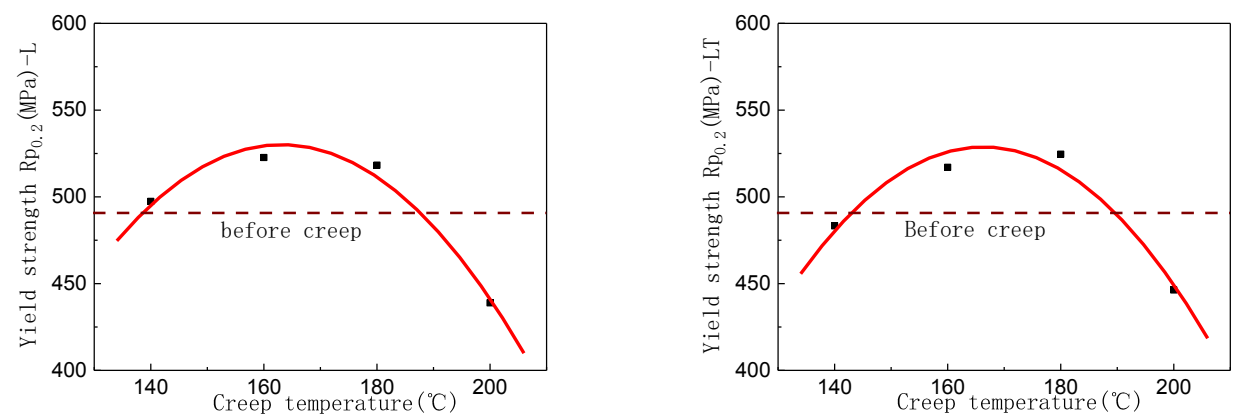

(b) Creep temperature vs. Yield strength
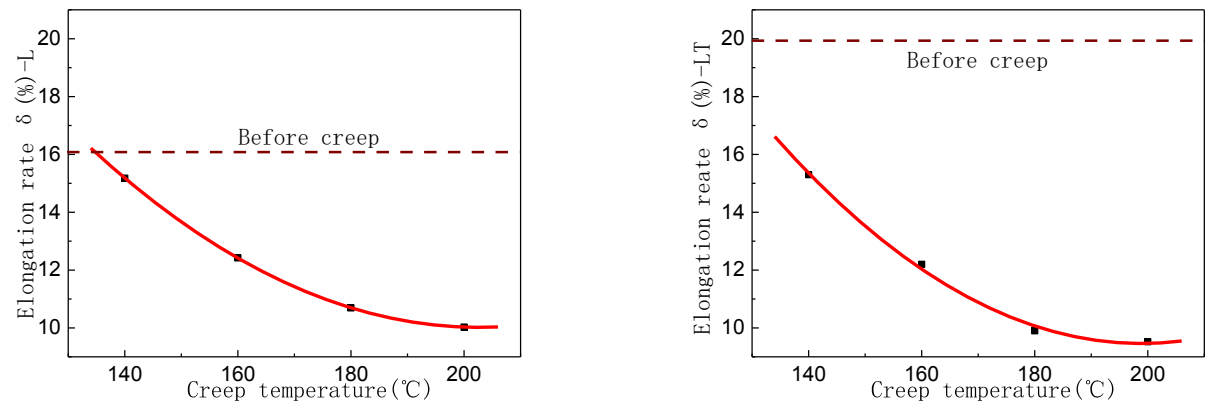

(C) Creep temperature vs. Elongation rate

Fig. 6 Relationships between creep temperature and material properties

Based on the influencing laws of the process parameters on material properties, the heat treatment parameters of $172{ }^{\circ} \mathrm{C} / 24 \mathrm{~h}$ is selected. There are no significant changes in grain size and the microstructures before and after creep forming, which is shown is Fig. 7. Because the temperature of creep forming is low and the time period of creep forming is short. The mechanical properties test also can demonstrate that this Al-Li alloy is no much overaged from T8 status.
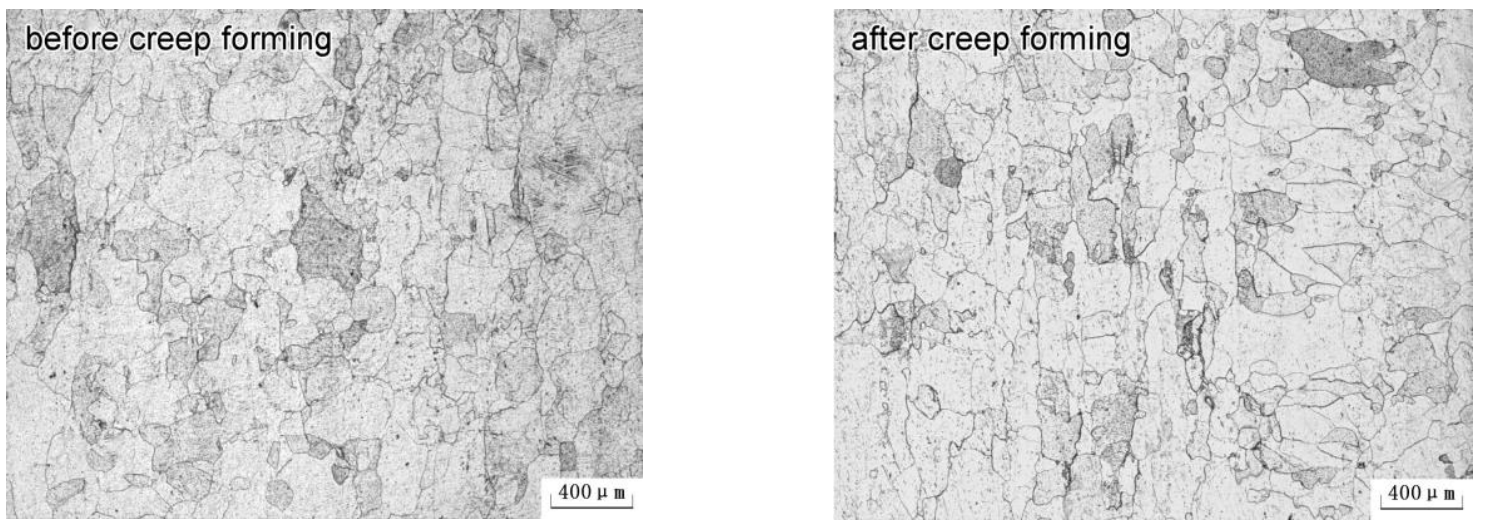

Fig. 7 Microstructure of the material before and after creep forming

\section{Creep forming experiment of a typical structural component}

Fig. 8 shows a partial welded component of aircraft fuselage with single curvature radius of $\mathrm{R}=1000 \mathrm{~mm}$. The dimension size is $420 \times 400 \mathrm{~mm}$ and it has four "L"-section welded ribs spacing $120 \mathrm{~mm}$. The thickness of skin part is $1.5 \mathrm{~mm}$. The ribs are welded by friction stir welding. 


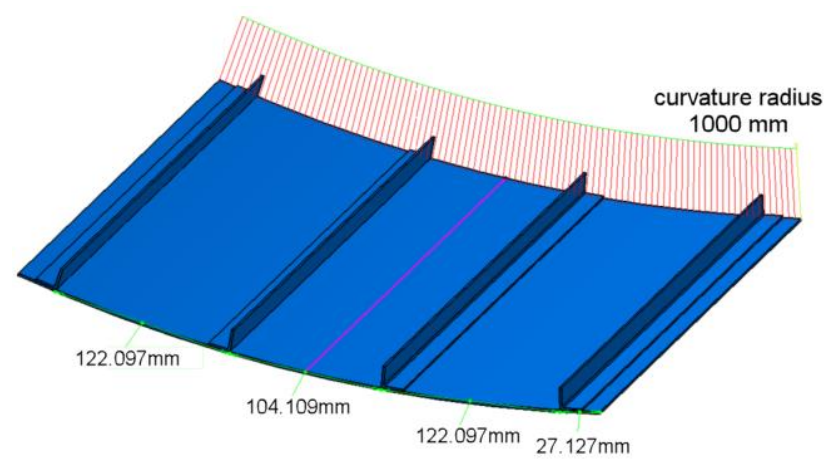

Fig. 8 Typical structure part component

Based on the relationship between the process parameters and formability obtained from fundamental experiments, the parameters of typical structural part component are designed as table 5. Pre-bend is imposed with special die as shown in figure 9 before creep forming.

Table 5. Creep forming parameters

\begin{tabular}{ll}
\hline Parameter & Value \\
\hline Time period, hour & 24 \\
Temperature, ${ }^{\circ} \mathrm{C}$ & 172 \\
Radius of pre-bend, $\mathrm{mm}$ & 185 \\
\hline
\end{tabular}

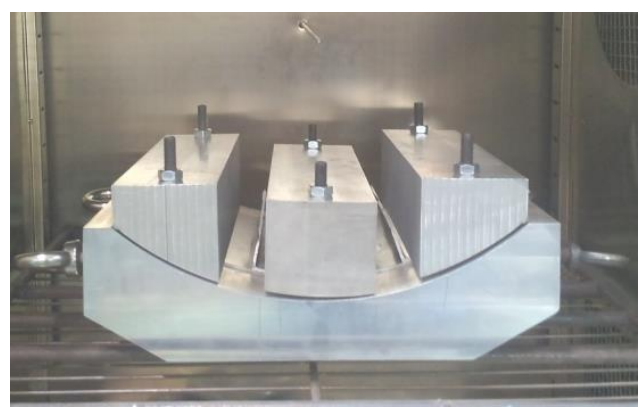

Fig. 9 Pre-bend part with tool

Fig. 10 and 11 show the part component before and after experiment. There are gaps of $15 \mathrm{~mm}$ and $18.5 \mathrm{~mm}$ between the bottom surface of part and the plane before creep forming. After forming process, the deformation caused by welding is reduced obviously due to the stress relief during creep aging. The gap between gauge and part surface is less than $0.5 \mathrm{~mm}$ in the acceptable error range, which confirmed the effective of equation model derived from fundamental experimental data. The main creep deformation occurs perpendicular to the friction stir welding direction, so the effect of welded region on creep forming can be ignored.

The uniaxial tension samples were cut from the creep formed structural panel and table 6 shows the mechanical properties. The tension strength and yield strength of both directions are increased, which demonstrate the effect of the process. 


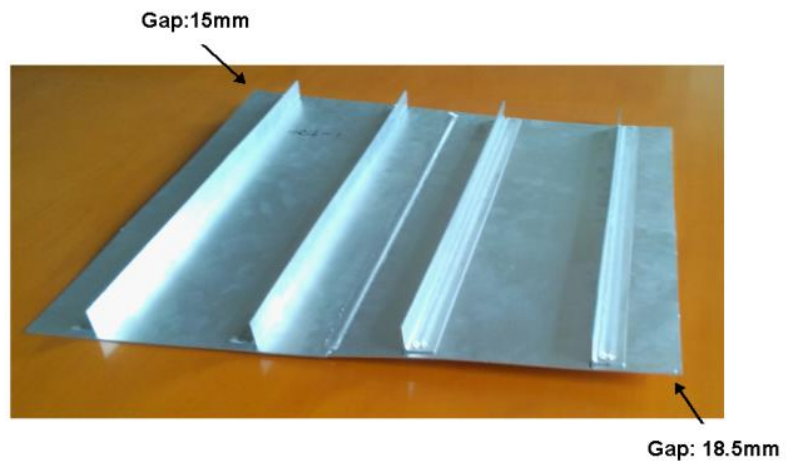

Fig. 10 Part before creep forming

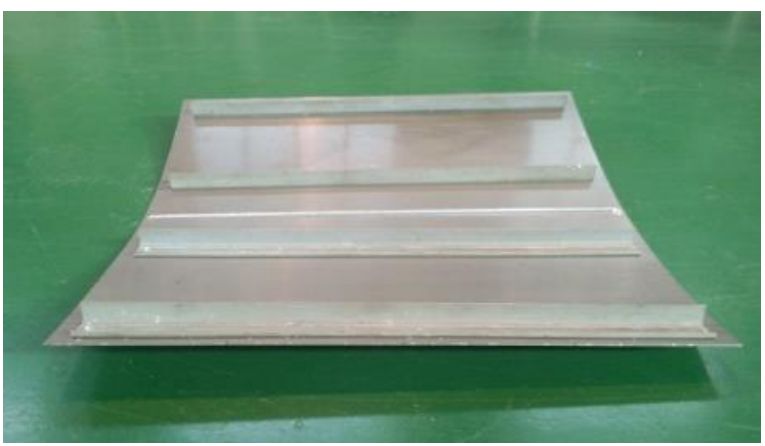

Fig. 11 Part after creep forming

Table 6. Mechanical properties of the alloy after creep forming

\begin{tabular}{lcccc}
\hline Materials & $\begin{array}{c}\text { Tension } \\
\text { Direction }\end{array}$ & $\begin{array}{c}\text { Tensile strength } \\
\mathbf{M P a}\end{array}$ & $\begin{array}{c}\text { Yield strength } \\
\mathbf{M P a}\end{array}$ & $\begin{array}{c}\text { Elongation } \\
\mathbf{\%}\end{array}$ \\
\hline \multirow{2}{*}{$\mathrm{Al}-\mathrm{Li}-\mathrm{Cu}-\mathrm{Mg}$} & $\mathrm{LD}$ & 536.4 & 510.6 & 13.3 \\
\cline { 2 - 5 } & $\mathrm{TD}$ & 569.2 & 520.6 & 10.6 \\
\hline
\end{tabular}

\section{Conclusion}

For creep forming on the new Al-Li-Cu-Mg alloy, the most influential factor is the temperature, the next is time period, and the last is radius of pre-bend. The springback ratio decreases with the temperature and time period, increases with radius of pre-bend.

The equation model derived from experimental data by regressive analysis method is accurate and can describe the relationship between the springback ratio and creep parameters, which is validated by creep forming experiment of a typical welded reinforced panel component.

\section{References}

1. WU Xiuliang, LIU Ming, ZANG Jinxin, et al. Research Progress and Aerospace Application of Aluminium Lithium Alloys [J]. Materials Review, 2016, 30(28): 571-585.

2. ZHENG Zi-qiao, LI Jin-feng, CHEN Zhi-guo, et al. Alloying and microstructural evolution of Al-Li alloys [J]. The Chinese Journal of Nonferrous Metals, 2011, 21(10): 2337-2351.

3. YANG Shoujie, LU Jian, FENG Zhaohui, et al. The History of Al-Li Alloys and the Research Development in China [J]. Materials Review, 2014, 28(24): 430-435. 
4. XU Jinjun, KANG Wei, DOU Changbing. Research status and development trends of Al-Li alloys for aeronautic and astronautic industry [J]. Ordnance Material Science and Engineering, 2017, 40(3): 132-136.

5. Wei Xiuyu, Zheng Ziqiao, Pan Zhengrong, et al. The Role of Plastic Deformation on Microstructure and Mechanical Properties of 2197 Al-Li Alloy [J]. Rare Metal Materials and Engineering, 2008, 37(11): 1996-1999.

6. GAN Zhong XIONG Wei ZHANG Zhi-guo. Springback prediction of age-forming for 2124 Aluminium alloy [J]. Journal of Plasticity Engineering, 2009, 16(3): 140-144.

7. LI Hong, BAI Xue-piao, ZENG Yuan-song, MENG Qiang. Effect of processing parameter on springback during creep forming of Al-Li alloy 2198 butt-joined by FSW [J]. Journal of Plasticity Engineering, 2012, 20(6): 108-111.

8. Holman M C. Autoclave age forming large Aluminium aircraft panels [J]. Journal of Mechanical Working Technology, 1989, 20(9): 477-488.

9. Foroudastan S, Peddision J, Holman M C. Application of a unified viscoplastic model of simulation of autoclave age forming [J]. Journal of Engineering Materials and Technology, 1992, 114(1): 71-76.

10. Lin J, Ho K C, Dean T A. An integrated process for modelling of precipitation hardening and springback in creep forming [J]. International Journal of Machine Tools and Manufacture, 2006, 46(11): 1266-1270.

11. Department of mathematics and mechanics of Peking University. Orthogonal design methods [M]. Beijing: Petroleum Chemical Industry Press, 1976:17-43 